\title{
The dynamics of questing ticks collected for 164 consecutive months off the vegetation of two landscape zones in the Kruger National Park (1988-2002). Part II. Rhipicephalus appendiculatus and Rhipicephalus zambeziensis
}

\author{
Authors: \\ Arthur M. Spickett ${ }^{1}$ \\ Gordon J. Gallivan ${ }^{2}$ \\ Ivan G. Horak ${ }^{3,4}$ \\ Affiliations: \\ ${ }^{1}$ Parasites, Vectors \\ \& Vector-borne \\ Diseases Programme, \\ Onderstepoort Veterinary \\ Institute, South Africa \\ ${ }^{2} 187$ Cluny Street, Ottawa, \\ Canada \\ ${ }^{3}$ Department of Veterinary \\ Tropical Diseases, \\ University of Pretoria, \\ South Africa \\ ${ }^{4}$ Department of Zoology \\ and Entomology, University \\ of the Free State, \\ South Africa \\ Correspondence to: \\ Arthur Spickett \\ Email: \\ SpickettAM@arc.agric.za \\ Postal address: \\ Private bag X05, \\ Onderstepoort 0110 \\ South Africa \\ Dates: \\ Received: 27 Sept. 2010 \\ Accepted: 14 Dec. 2010 \\ Published: 24 Mar. 2011 \\ How to cite this article: \\ Spickett, A.M., Gallivan, \\ G.J. \& Horak, I.G., 2011, \\ 'The dynamics of questing \\ ticks collected for 164 \\ consecutive months \\ off the vegetation of \\ two landscape zones \\ in the Kruger National \\ Park (1988-2002). \\ Part II. Rhipicephalus \\ appendiculatus \\ and Rhipicephalus \\ zambeziensis', \\ Onderstepoort Journal \\ of Veterinary Research \\ 78(1): Art. \#233, 9 pages. \\ doi:10.4102/ojvr.v78i1.233
}

The study aimed to assess the long-term population dynamics of questing Rhipicephalus appendiculatus and Rhipicephalus zambeziensis in two landscape zones of the Kruger National Park (KNP). Ticks were collected by dragging the vegetation monthly in three habitats (grassland, woodland and gully) at two sites in the KNP (Nhlowa Road and Skukuza) from August 1988 to March 2002. Larvae were the most commonly collected stage of both species. More R. appendiculatus were collected at Nhlowa Road than at Skukuza, with larvae being most abundant from May to August, while nymphs were most abundant from August to December. Larvae were most commonly collected in the gullies from 1991 to 1994, but in the grassland and woodland habitats from 1998 onwards. Nymphs were most commonly collected in the grassland and woodland. More R. zambeziensis were collected at Skukuza than at Nhlowa Road, with larvae being most abundant from May to September, while nymphs were most abundant from August to November. Larvae and nymphs were most commonly collected in the woodland and gullies and least commonly in the grassland $(p<0.01)$. The lowest numbers of $R$. appendiculatus were collected in the mid-1990s after the 1991/1992 drought. Rhipicephalus zambeziensis numbers declined after 1991 and even further after 1998, dropping to their lowest levels during 2002. The changes in numbers of these two species reflected changes in rainfall and the populations of several of their large herbivore hosts, as well as differences in the relative humidity between the two sites over time.

\section{Introduction}

The population dynamics of ticks are influenced by a complex interaction between ticks, their hosts and their environment. Many studies have examined these associations, but most have been of relatively short duration - typically 1-2 years - and there is little information on longer-term changes in tick populations.

In an earlier publication (Horak, Gallivan \& Spickett 2011) we described the changes in the numbers of questing ticks and the populations of two major tick species, Amblyomma hebraeum and Rhipicephalus decoloratus, collected by monthly dragging at two sites in the Kruger National Park (KNP) over a period of 164 months. In the present publication we describe the changes in the populations of two other commonly collected tick species, Rhipicephalus appendiculatus and Rhipicephalus zambeziensis. These morphologically similar species are sympatric in the KNP and are commonly collected from medium to large-sized ungulates (Horak et al. 1983a; Horak, De Vos \& Brown 1983b; Horak et al. 1992; Horak et al. 2003). The relative intensities of infestation of $R$. appendiculatus and $R$. zambeziensis on antelopes vary. While host preference may be a factor, the variation in the relative intensities of infestation on impalas (Aepyceros melampus) collected at several sites (Horak et al. 2003) suggests that site may also be an important component. However, there is limited information on the factors determining the distribution of these two ticks in the KNP.

In Zimbabwe, R. zambeziensis occurs in hotter, drier areas of the great river valleys of the northern, north-western and southern parts of the country, whereas $R$. appendiculatus is found at higher elevations in the eastern and southern parts, with an intermediate zone where the distributions overlap (Norval, Walker \& Colborne 1982). Minshull and Norval (1982) described factors influencing the spatial distribution of $R$. appendiculatus in Kyle Recreational Park, Zimbabwe and Norval and Perry (1990) described factors influencing the disappearance of introduced 
R. appendiculatus from the Zimbabwe lowveld. Perry et al. (1990) used computer models to assess the effect of climate and vegetation on the distribution of $R$. appendiculatus in Africa, while Olwoch et al. (2007) used computer models to assess the effect of climate change on Rhipicephalus species, including $R$. appendiculatus and $R$. zambeziensis, in subSaharan Africa. Because the present study was conducted over a period of 164 months, and began towards the end of a wet period in the KNP and continued through the dry period into a subsequent wet period (Horak et al. 2011), it provided an opportunity to examine the effect of changes in rainfall on the population dynamics of these two species in the KNP.

\section{Materials and methods}

The KNP is a large nature reserve in north-eastern South Africa covering nearly 2 million hectares. Within the KNP there are five vegetation types (Acocks 1988) and 35 landscape zones (Gertenbach 1983). The study sites at Skukuza and Nhlowa Road, climate, methods of tick collection and statistical methods employed have been described in detail by Horak et al. (2011). Records of annual (June-May) rainfall and mean monthly relative humidity at 08:00 and 14:00 were obtained from the weather stations at Skukuza and Lower Sabie, the two rest camps closest to the study sites, for the period of the study.

Briefly, questing ticks were collected monthly by dragsampling the vegetation with flannel strips, including flannel leggings worn by the drag operator (Spickett et al. 1992) at two identified KNP sites. This collection method favours the recovery of larvae (Spickett et al. 1991), although nymphs and adults were consistently recovered. The Nhlowa Road site was in Gertenbach's (1983) Landscape Zone 17 (MarulaKnob thorn savanna) and the Skukuza site was in Landscape Zone 4 (Thickets of the Sabie and Crocodile Rivers). Three drags, approximately $250 \mathrm{~m}$ in length, were made monthly in each of three visually selected habitats, namely grassland, woodland and gully. After each drag the ticks on the flannel strips and the leggings were removed using sharp-pointed forceps and stored in 70\% ethyl alcohol in internally labelled, plastic-stoppered glass vials for later identification and quantification.

Sampling commenced in August 1988 and continued in each habitat at the two localities until March 2002, unless when there was heavy rainfall or a bush fire, or elephants, African buffaloes or lions visible in a habitat.

\section{Results}

\section{Climate data}

Annual rainfall (June-May) at the Skukuza rest camp averaged $609 \mathrm{~mm}$ for the period of the study, with a range of $275 \mathrm{~mm}-1122 \mathrm{~mm}$ (Figure 1a). Average annual rainfall at the Lower Sabie rest camp, the closest climate station to the Nhlowa Road site, was similar to that at Skukuza, as was the mean monthly relative humidity (Figure 1b).

\section{Rhipicephalus appendiculatus}

Table 1 shows that $R$. appendiculatus was the second most commonly collected tick at Nhlowa Road, but was relatively uncommon at Skukuza $(p<0.001)$. Larvae were the most commonly collected stage at both localities, comprising $97.3 \%$ of the collection at Nhlowa Road and $89.5 \%$ of the collection at Skukuza.

At Nhlowa Road there was a significant difference between the number of larvae and nymphs collected over the years $(p<0.01)$. The numbers increased until the early 1990s, declined markedly until 1996/1997 and then increased until 2000 (Figure 2a). However, much smaller numbers of larvae and nymphs were collected around the turn of the century than in the early 1990s. There was a peak in adult tick numbers in 1990/1991, while none were collected from 1996 to 1998, after which the numbers increased. With the exception of $1990 / 1991$, more adults were collected from 1998/1999 to $2001 / 2002$ than in the early 1990s. At Skukuza 35.5\% of the R. appendiculatus larvae were collected in 1993, 41.0\% in 2000 and 11.7\% in 2001. None were collected from 1994 to 1997. The high number collected in 1993 was probably an anomaly, because 91 of the 97 larvae collected that year came from a single drag. Few nymphs or adults were collected at Skukuza and none were collected there from the mid-1990s to 2000 (Figure 2b).

At Nhlowa Road $R$. appendiculatus larvae were collected from March to December, with peak collections from June to August (Figure 3a). Nymphs were collected throughout the year, with peak collections from August to November, while adults were collected from January to July, with peak collections in March and April. At Skukuza the seasonal activity was much more restricted (Figure 3b). Larvae were collected from April to September, with a peak in June, nymphs were collected from July to January, with a peak from August to October, and adults were collected from February to August, with a peak in April.

There was a significant difference in the seasonal patterns of collections of $R$. appendiculatus larvae over the years at Nhlowa Road $(p<0.001)$. In years when large numbers of larvae were collected, the peaks were much higher and the season typically stretched from April to November, with the peak in July or August. However, in years when relatively few larvae were collected, the collections were from April or May to August or September, with peaks in June or July, similar to the pattern at Skukuza.

The numbers of $R$. appendiculatus larvae were not significantly correlated with annual rainfall or rainfall during their active period (April-November) at either site, but were negatively correlated $(r=-0.71 ; p<0.05)$ with winter rainfall at Nhlowa Road. The numbers of nymphs and adults were not significantly correlated with annual rainfall at either site.

The numbers of $R$. appendiculatus larvae did not differ significantly between the three habitats $(p=0.23)$. However, there was a significant year-by-habitat interaction $(p=0.004)$. At Nhlowa Road, $R$. appendiculatus larvae were 


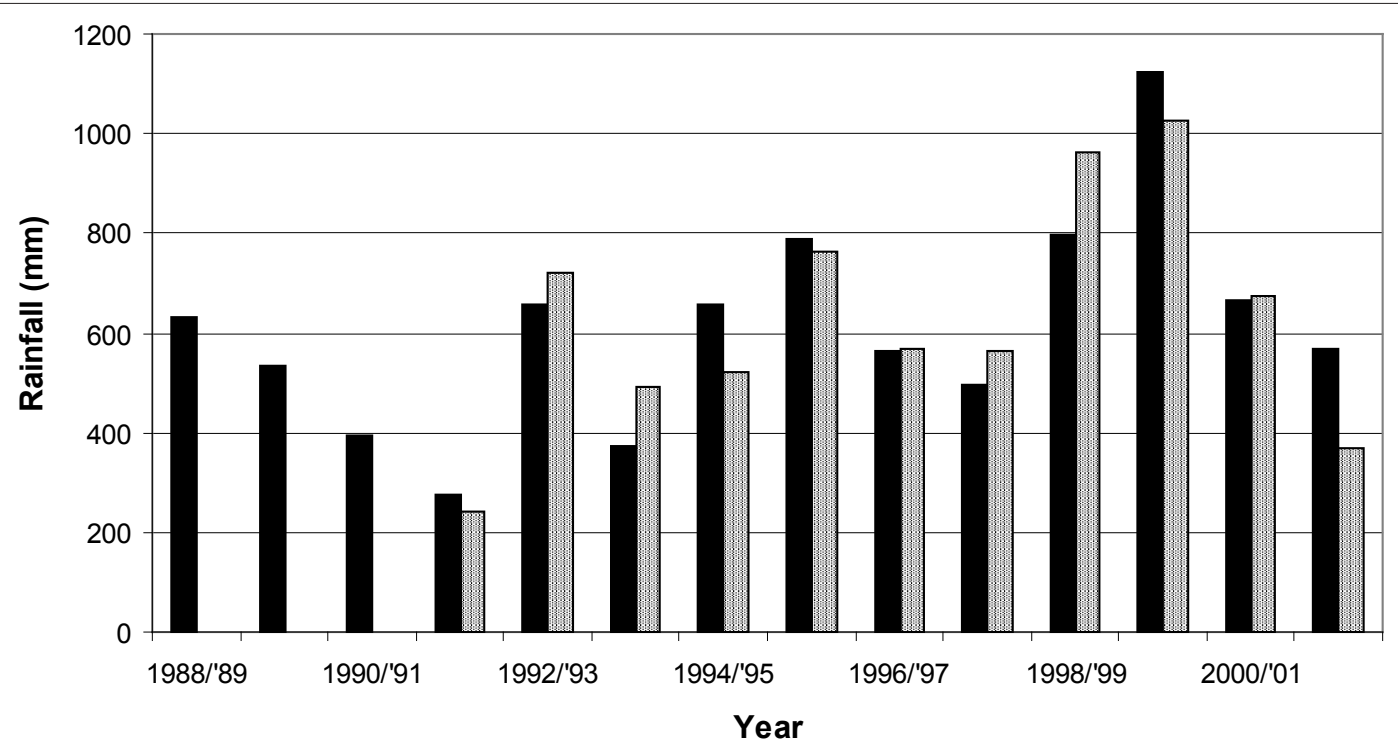

- Skukuza $\square$ Lower Sabie

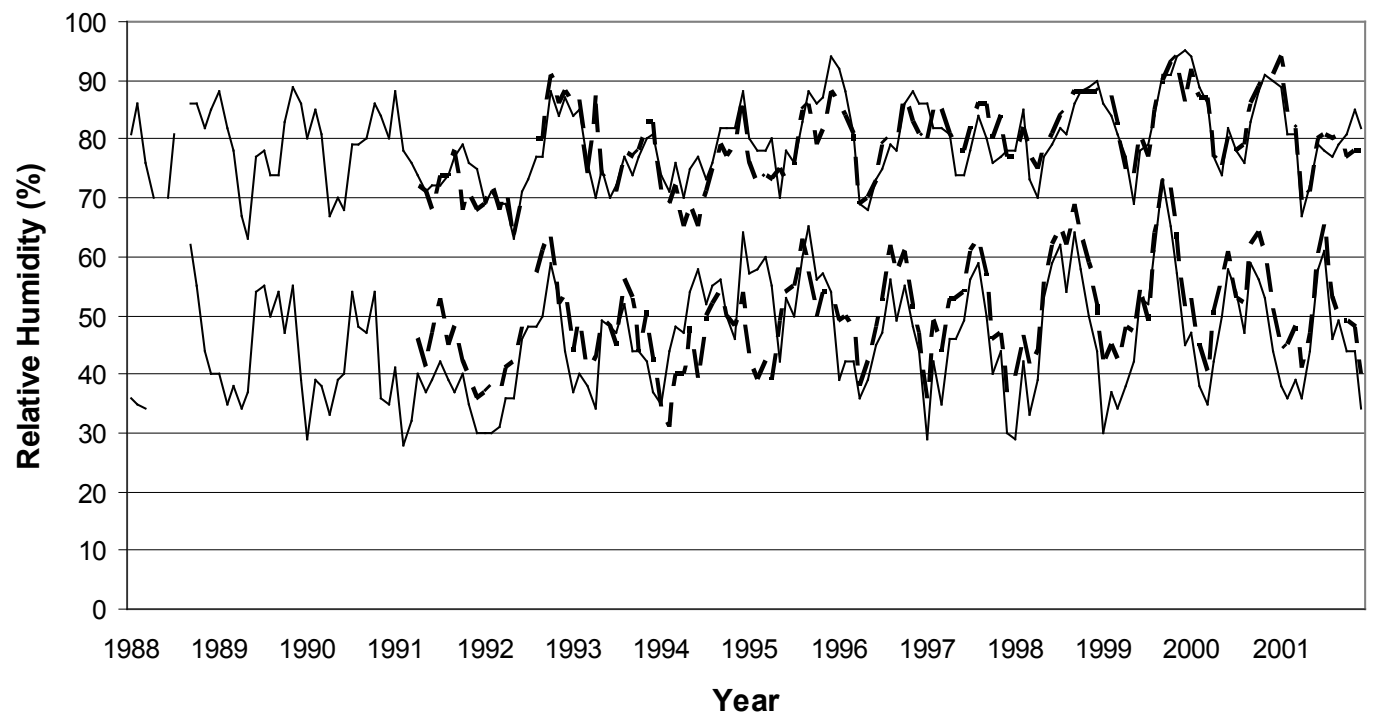

Upper set of curves represents humidity readings at 08:00; the lower set represents humidity readings at 14:00 at each of the sites. Weather readings commenced only during 1991/1992 at Lower Sabie.

FIGURE 1: a) Annual (June-May) rainfall and b) mean monthly relative humidity during the study period at Skukuza and Lower Sabie.

TABLE 1: Number of Rhipicephalus appendiculatus and Rhipicephalus zambeziensis collected in the Kruger National Park by dragging at the Skukuza and Nhlowa Road sites from August 1988 to March 2002.

\begin{tabular}{|c|c|c|c|c|c|}
\hline \multirow[t]{2}{*}{ Species } & \multirow[t]{2}{*}{ Stage } & \multicolumn{2}{|c|}{ Skukuza (Zone 4) } & \multicolumn{2}{|c|}{ Nhlowa Road (Zone 17) } \\
\hline & & $N$ & $\%$ & $N$ & $\%$ \\
\hline \multirow[t]{3}{*}{ R. appendiculatus } & LL & 273 & 0.22 & 35554 & 16.80 \\
\hline & NN & 23 & 0.02 & 833 & 0.39 \\
\hline & AA & 9 & 0.007 & 139 & 0.07 \\
\hline \multirow[t]{3}{*}{ R. zambeziensis } & LL & 44914 & 35.70 & 2387 & 1.13 \\
\hline & NN & 3202 & 2.55 & 328 & 0.16 \\
\hline & AA & 25 & 0.02 & 9 & 0.004 \\
\hline Other species & $\mathrm{LL}, \mathrm{NN}, \mathrm{AA}$ & 77364 & 61.47 & 172319 & 81.44 \\
\hline Total & - & 125810 & - & 211569 & - \\
\hline
\end{tabular}

$N$, number of ticks collected at the site; \%, percentage of the number of ticks collected at the site.

AA, adults; LL, larvae; NN, nymphs. 
most commonly collected in the gullies and least frequently in the grassland from 1991 to 1994, but they were most commonly collected in the grassland and woodland and least frequently in the gullies from 1998 to 2001 (Figure 4a). Similar patterns were seen at Skukuza, but they were less pronounced. The distribution among habitats did not differ by month (Table 2).

At Nhlowa Road $R$. appendiculatus nymphs were most commonly collected in the grassland and woodland and least frequently in the gullies. There was a marginally significant year-by-habitat interaction $(p=0.06)$, with higher numbers in the grassland and woodland from 1988/1989 to $1991 / 1992$ and from 1998/1999 to 2000/2001 (Figure 4b). The distribution among habitats did not differ by month, but the numbers were much higher in the grassland than in the gullies from August to November. There was no significant difference between habitats at Skukuza, but nymphs were most commonly collected in the woodland and gullies and least commonly in the grassland. At Nhlowa Road, 69 of the $139 R$. appendiculatus adults were collected in the gullies, as were eight of the nine adults at Skukuza.

\section{Rhipicephalus zambeziensis}

Rhipicephalus zambeziensis was the most commonly collected tick at Skukuza, accounting for $38.3 \%$ of the ticks collected at this site. The numbers of $R$. zambeziensis collected were significantly higher at Skukuza than at Nhlowa Road ( $p=$ 0.001). Larvae were the most commonly collected stage of R. zambeziensis, accounting for $93.3 \%$ of the collections at Skukuza and $87.6 \%$ at Nhlowa Road.

The numbers of $R$. zambeziensis larvae varied significantly between years $(p<0.001)$ and there was a significant year-bysite interaction $(p<0.001)$. At Skukuza the numbers of larvae declined after 1991 and remained relatively constant until 1999/2000, after which they declined rapidly (Figure 5a). At Nhlowa Road there were two peaks in the number of larvae, from 1991 to 1993 and from 1995 to 1998 (Figure 5b).

The numbers of nymphs also varied significantly between years $(p<0.001)$, with a significant year-by-site interaction $(p<0.001)$. At Skukuza the numbers of nymphs were relatively constant from 1988/1989 to 1991/1992, declined and then remained relatively constant until 1999/2000, after which the numbers declined markedly (Figure 5a). At Nhlowa Road the numbers of nymphs varied among years, with peaks in 1992/1993, 1995/1996 and 1998/1999 (Figure $5 b)$. At Skukuza, $68 \%$ of the adults were collected during 3 years, namely 1990/1991, 1998/1999 and 2000/2001. At Nhlowa Road four of the nine $R$. zambeziensis adults were collected in 1998/1999.

At Skukuza larvae were collected in all months except January, with peak collections from June to September (Figure 6a). There was a significant year-by-month interaction $(p<0.001)$ caused by year-to-year variation in the numbers collected during the peak period of activity rather than differences in the duration of the activity period. Nymphs were collected in all months except March and April, with a peak from August to October. Adults were collected from January to June, with a peak in March and April. At Nhlowa Road larvae were collected from April to November, nymphs from May to December, and adults from January to May (Figure 6b). The peak activity periods for all stages were similar to those at Skukuza.

There was a negative correlation $(r<-0.5 ; p<0.1)$ between the numbers of larvae collected and seasonal rainfall at both sites, and a significant negative correlation with rainfall during their activity period (April-November) at Skukuza $(r=-0.59 ; p=0.03)$, but not at Nhlowa Road. The numbers of nymphs were not significantly correlated with rainfall.

As shown in Table 2, R. zambeziensis larvae and nymphs were most commonly collected in the woodland and gullies and least commonly collected in the grassland $(p<0.01)$. The peak numbers were higher and the duration of activity was longer in woodland and gullies than in grassland. The difference in distribution between habitats was statistically significant at Skukuza $(p<0.001)$, but not at Nhlowa Road $(p>0.1)$. The distribution of larvae and nymphs among habitats was consistent over months and years (Figures $7 \mathrm{a}$ and b). Adults were most commonly collected in the gullies at both sites.

\section{Discussion \\ Rhipicephalus appendiculatus}

Rhipicephalus appendiculatus is a three-host tick. Its preferred wild hosts are African buffaloes, elands (Taurotragus oryx), the larger tragelaphine antelopes and waterbuck (Kobus ellipsiprymnus), although the smaller antelopes are also good hosts of its immature stages (Horak et al. 2003; Horak, Golezardy \& Uys 2007; Walker, Keirans \& Horak 2000;). It was the second most commonly collected tick at Nhlowa Road, but was relatively uncommon at Skukuza (Table 1).

At Nhlowa Road the numbers of $R$. appendiculatus increased from 1988/1989 to a peak in 1991/1992 and then declined markedly through the mid-1990s. The numbers increased again in the late 1990s, but were less than $10 \%$ of the numbers in the early 1990s. The reason for the increase in numbers from 1988/1989 to 1991/1992 is unclear as many of the major ungulate populations were already declining (Ogutu \& OwenSmith 2005) and the numbers of the other major tick species, A. hebraeum and $R$. decoloratus, were relatively constant (Horak et al. 2011). However, Gallivan et al. (1995) noted higher burdens of adult $R$. appendiculatus and Rhipicephalus muehlensi, another ear tick, on impalas in an unmanaged, overgrazed area in Swaziland than on impalas in an adjacent managed area. Impalas in poorer condition were more heavily infested with adult ticks. This could suggest that an increase in adult survival on the hosts may have contributed to the increase in the numbers of questing $R$. appendiculatus up to $1991 / 1992$. The decline in the numbers of $R$. appendiculatus after 1991/1992 coincided with the decline in the populations of large herbivores and other major tick species following the 1991/1992 drought. However, the numbers of 


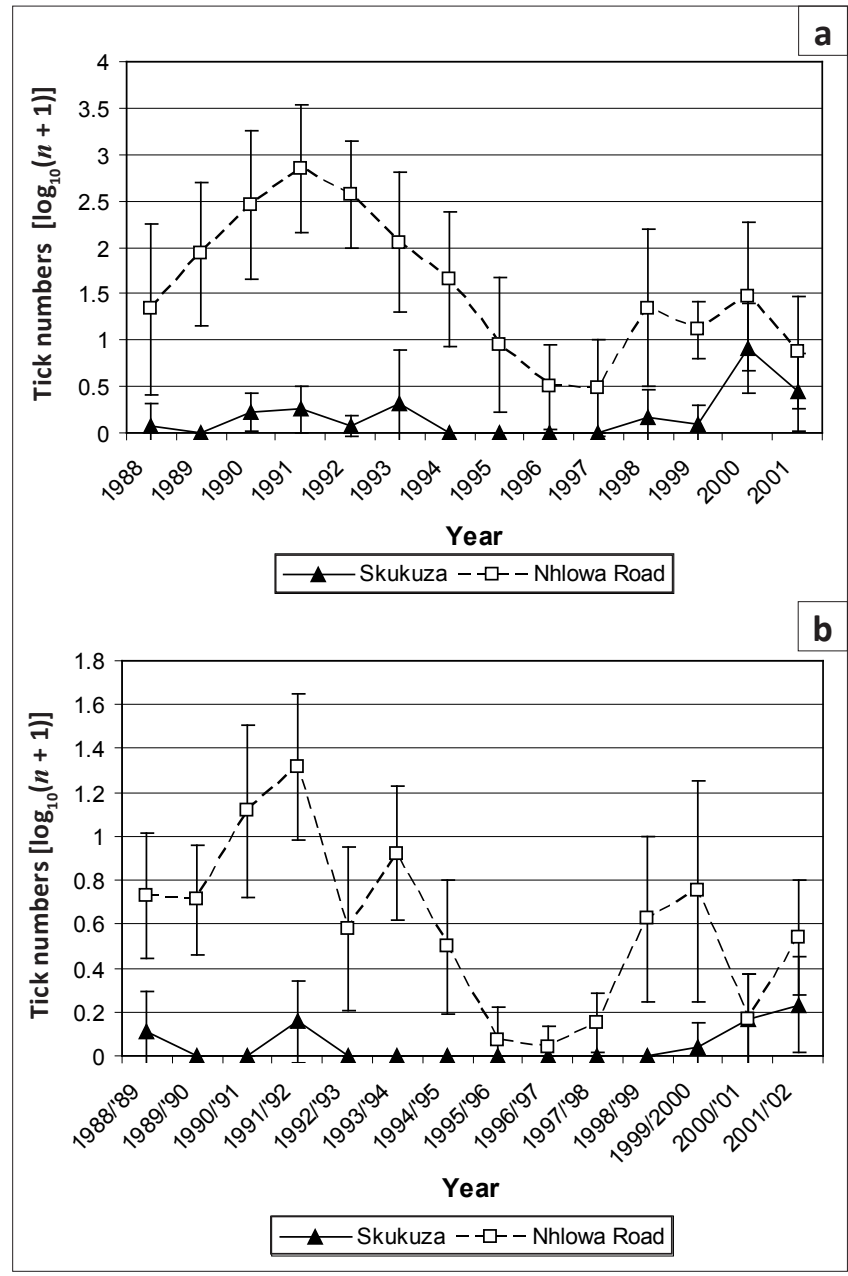

FIGURE 2: Mean ( $\pm 95 \%$ confidence interval) monthly collections of Rhipicephalus appendiculatus a) larvae and $\mathrm{b}$ ) nymphs during the active periods by year at Nhlowa Road and Skukuza.

$R$. appendiculatus remained low, and it was the only major tick species that did not exhibit a substantial increase in numbers towards the turn of the century (Horak et al. 2011). The lack of recovery towards the turn of the century probably accounts for the negative correlation observed between winter rainfall and the number of questing larvae.

Horak, Spickett \& Braack (2000) noted that there seems to be a considerable lag phase between low annual rainfall and the largest decrease in the numbers of questing $R$. appendiculatus. The nadir for $R$. appendiculatus collections was not reached until 1996/1997; between 2 and 4 years after the nadirs for the other major tick species (Horak et al. 2011). Vegetation analyses by the South African National Parks (SANParks) staff during and after the drought of 1991/1992 indicated that the greatest proportion of bare soil surface occurred during 1996/1997, 5 years after the drought (Horak, Spickett \& Braack 2000). Short et al. (1989a, 1989b) reported both reduced fecundity and lower survival of $R$. appendiculatus in short grass habitats in Zimbabwe. Thus, the decrease in cover probably reduced both the fecundity and the survival of the free-living stages of $R$. appendiculatus, and exacerbated the decline in numbers caused by the decrease in host populations. Dry stress during a drought period was an important contributing factor
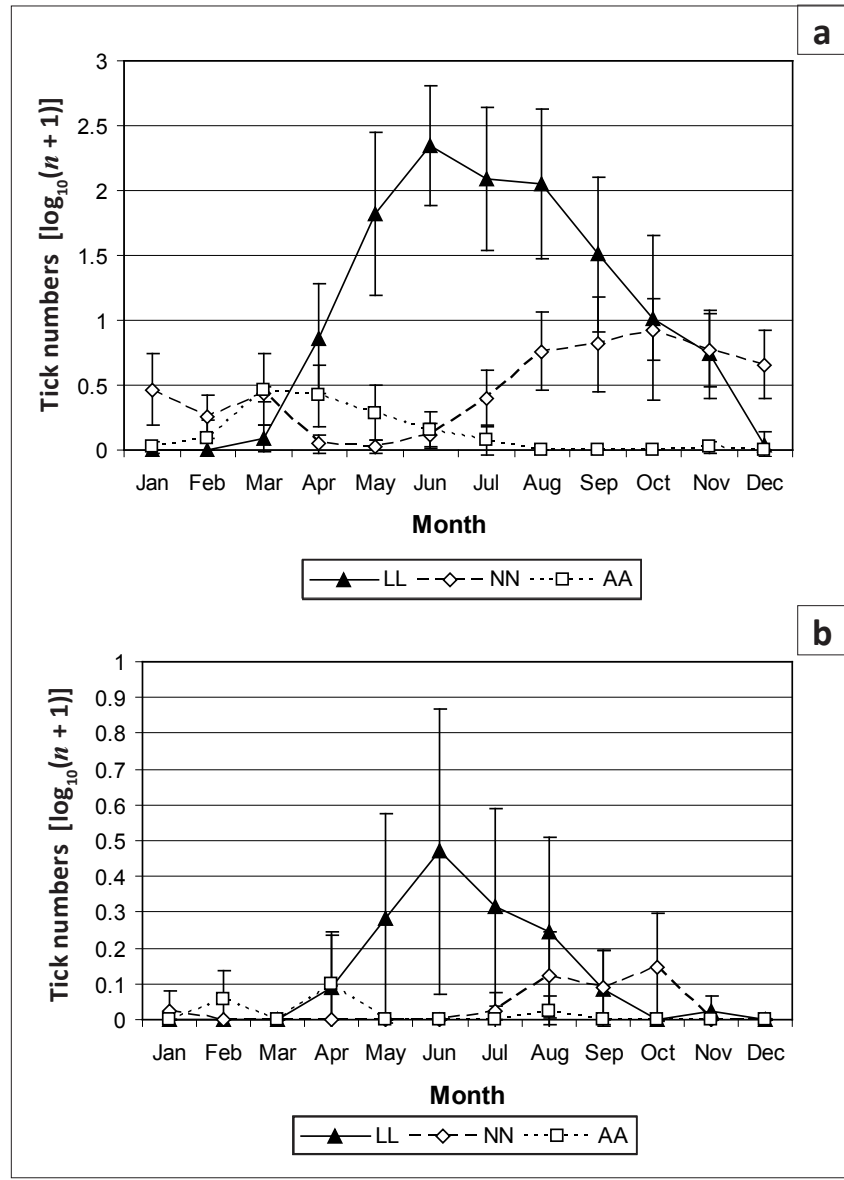

AA, adults; LL, larvae; NN, nymphs.

FIGURE 3: Mean ( $\pm 95 \%$ confidence interval) collections of all stages of Rhipicephalus appendiculatus per month at a) Nhlowa Road and b) Skukuza.

to the disappearance of $R$. appendiculatus that had been introduced into the lowveld of Zimbabwe (Norval \& Perry 1990).

With the exception of a peak in 1993, most $R$. appendiculatus at Skukuza were collected around the turn of the century during a period of above-average rainfall. The apparent peak in 1993 was probably an anomaly because 91 of the 97 larvae were collected from a single drag. In a study on the dispersal patterns of ticks under field conditions, Rechav (1979) observed that R. appendiculatus larvae remained within $50 \mathrm{~cm}$ of their release point. Thus, the high number probably represents the capture of larvae from a single female, or group of females, that had detached at one location rather than an increase in tick numbers that year.

Peak numbers of $R$. appendiculatus larvae were collected from June to August (Figure 2a), peak numbers of nymphs from August to November, and peak numbers of adults in March and April. The seasonality of $R$. appendiculatus at Nhlowa Road was similar to that on adult impala rams examined approximately $16 \mathrm{~km}$ south of the Nhlowa Road site (Horak et al. 2003) and to that of free-living ticks collected by dragsampling in an earlier survey (Spickett et al. 1992).

The seasonality of $R$. appendiculatus larvae differed between years at Nhlowa Road. In years during which large numbers of larvae were collected, the season extended from April to November, with a peak in July or August, whereas in 
TABLE 2: Mean monthly tick collections $\left[\log _{10}(n+1)\right]$ by habitat.

\begin{tabular}{|c|c|c|c|c|c|c|c|c|c|c|}
\hline \multirow[t]{2}{*}{ Species } & \multirow[t]{2}{*}{ Stage } & \multicolumn{3}{|c|}{ Combined } & \multicolumn{3}{|c|}{ Skukuza (Zone 4) } & \multicolumn{3}{|c|}{ Nhlowa Road (Zone 17) } \\
\hline & & grassland & gully & woodland & grassland & gully & woodland & grassland & gully & woodland \\
\hline \multirow[t]{2}{*}{ R. appendiculatus } & $\mathrm{LL}^{+}$ & 0.501 & 0.591 & 0.546 & 0.095 & 0.075 & 0.078 & 0.896 & 1.093 & 1.000 \\
\hline & $\mathrm{NN}^{\ddagger}$ & 0.205 & 0.149 & 0.191 & 0.016 & 0.022 & 0.023 & $0.385^{\mathrm{a}}$ & $0.270^{\mathrm{b}}$ & $0.352^{\mathrm{a}, \mathrm{b}}$ \\
\hline \multirow[t]{2}{*}{ R. zambeziensis } & $\mathrm{LL}^{+}$ & 0.733 & $0.942^{\mathrm{a}}$ & $1.011^{\mathrm{a}}$ & 1.105 & $1.484^{\mathrm{a}}$ & $1.511^{\mathrm{a}}$ & 0.371 & 0.416 & 0.524 \\
\hline & $\mathrm{NN}^{\ddagger}$ & 0.270 & $0.462^{\mathrm{a}}$ & $0.483^{\mathrm{a}}$ & 0.470 & $0.746^{\mathrm{a}}$ & $0.793^{\mathrm{a}}$ & 0.072 & 0.181 & 0.177 \\
\hline Total number of ticks collected & - & $2.049^{a}$ & $2.139^{a}$ & 2.301 & $1.923^{\mathrm{a}}$ & $2.073^{a, b}$ & $2.229^{b}$ & 2.168 & 2.202 & 2.369 \\
\hline
\end{tabular}

$a, b$, habitats with the same superscript within a site were not significantly different $(p<0.05)$.

LL, larvae; NN, nymphs.

${ }^{+}$, April-November; ${ }^{\ddagger}$, July-February.

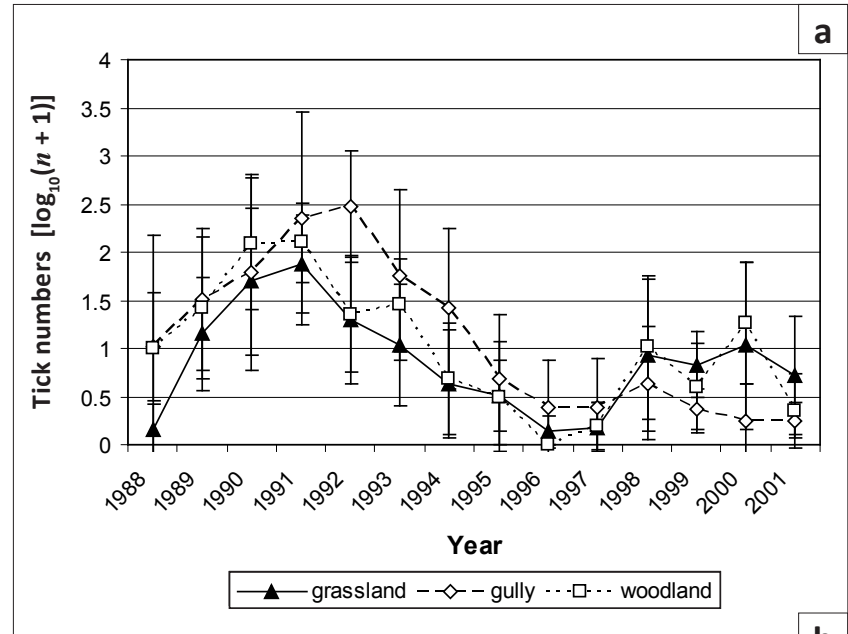

b

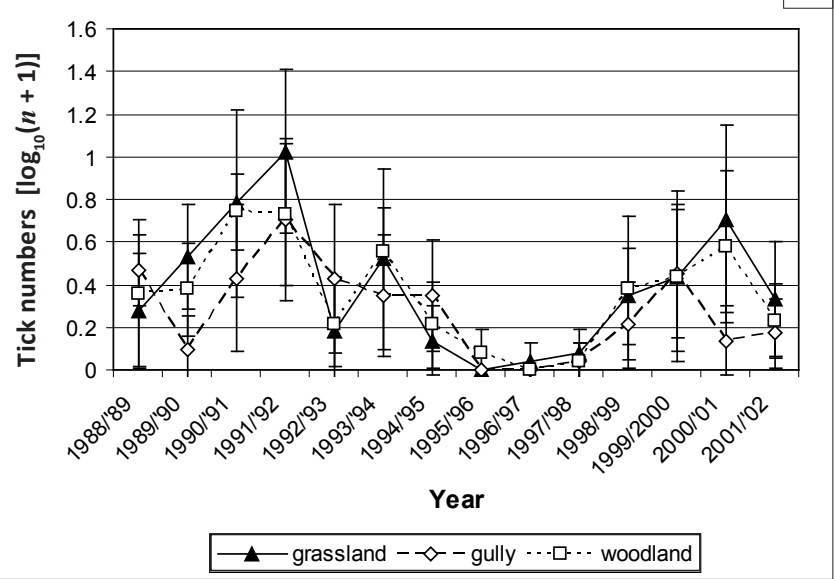

FIGURE 4: Mean ( $\pm 95 \%$ confidence interval) monthly collections of Rhipicephalus appendiculatus a) larvae and b) nymphs during the active periods by habitat and year at Nhlowa Road.

years during which relatively few larvae were collected, the collections were made from April or May to August or September, with peaks in June or July. The shorter activity period in the years with small populations may be explained by the decrease in fecundity and survival in short grass habitats (Short et al. 1989a, 1989b) that would reduce tick numbers later in the season.

The seasonality of $R$. appendiculatus larvae at Skukuza was similar to that observed in years with few ticks at Nhlowa Road. The peak periods of activity were approximately 1 month later and the duration of activity was 2 months shorter than the activity of $R$. appendiculatus on impalas in this landscape zone in 1980/1981 (Horak et al. 2003). However, the seasonality was similar to that on impalas and scrub
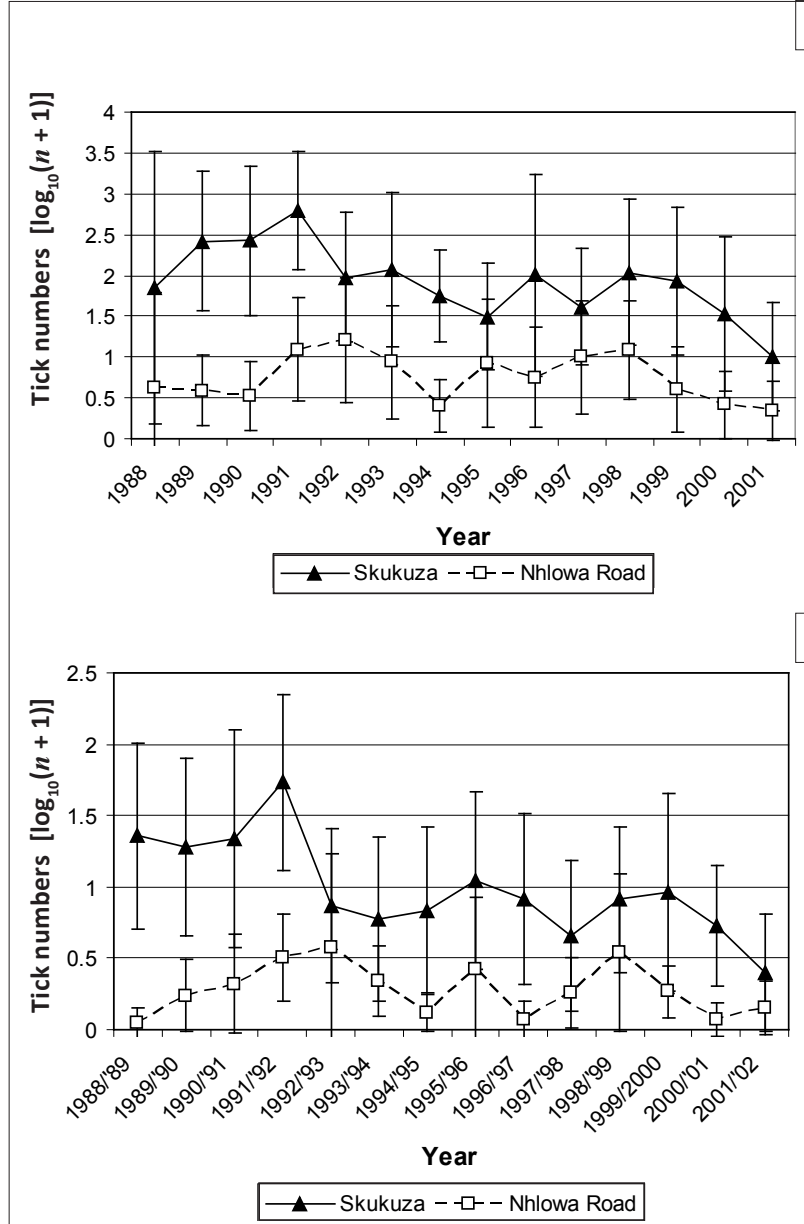

FIGURE 5: Mean ( \pm 95\% confidence interval) monthly collections of Rhipicephalus zambeziensis a) larvae and b) nymphs during the active periods of each year at Nhlowa Road and Skukuza.

hares (Lepus saxatilis) examined during the current study period (Horak et al. 1993; 2003) and in a study on the effects of burning in this landscape zone (Horak et al. 2006). As with the seasonal patterns at Nhlowa Road, the differences between the activity periods on impalas in 1980/1981 and the activity periods in the later studies may be explained by differences in vegetation. The impala collections in 1980/1981 were made at the end of a period of above-average rainfall (Whyte \& Joubert 1988) when there was a substantial grass mat (Horak, De Vos \& Braack 1995). In contrast, the collections during the current study were made during a period of belowaverage rainfall. In 1991/1992 there was a severe depletion of the standing grass and virtual disappearance of the grass mat that provided habitat for the free-living stages (Horak et al. 1995). 
The habitat distribution of $R$. appendiculatus differed by stage and over time. In the early years of this study, $R$. appendiculatus larvae were primarily collected in the gullies at both sites, whereas they were collected in the grasslands and woodlands around the turn of the century. The preferred hosts of $R$. appendiculatus adults are the large grazing ungulates such as elands and buffaloes, but they also utilise kudus (Tragelapus strepsiceros) and impalas when other hosts are not available (Horak et al. 1992, 2003, 2007). The decline in the populations of buffaloes and elands in the early years of this study probably increased the importance of kudus and impalas as hosts of adult $R$. appendiculatus. Buffaloes use woodland for shade, kudus are browsers and impalas are predominately browsers in the late summer (Wronski 2002). Thus, females would have detached in the gullies and woodland, where they and the hatching larvae would have had improved survival chance relative to those in the open grassland. The recovery of the grass sward and large herbivore populations towards the turn of the century would have increased use of the grasslands by the large grazers and impalas and improved larval survival in this environment.

At Nhlowa Road nymphs were collected most frequently in the grassland and least frequently in the gullies. This

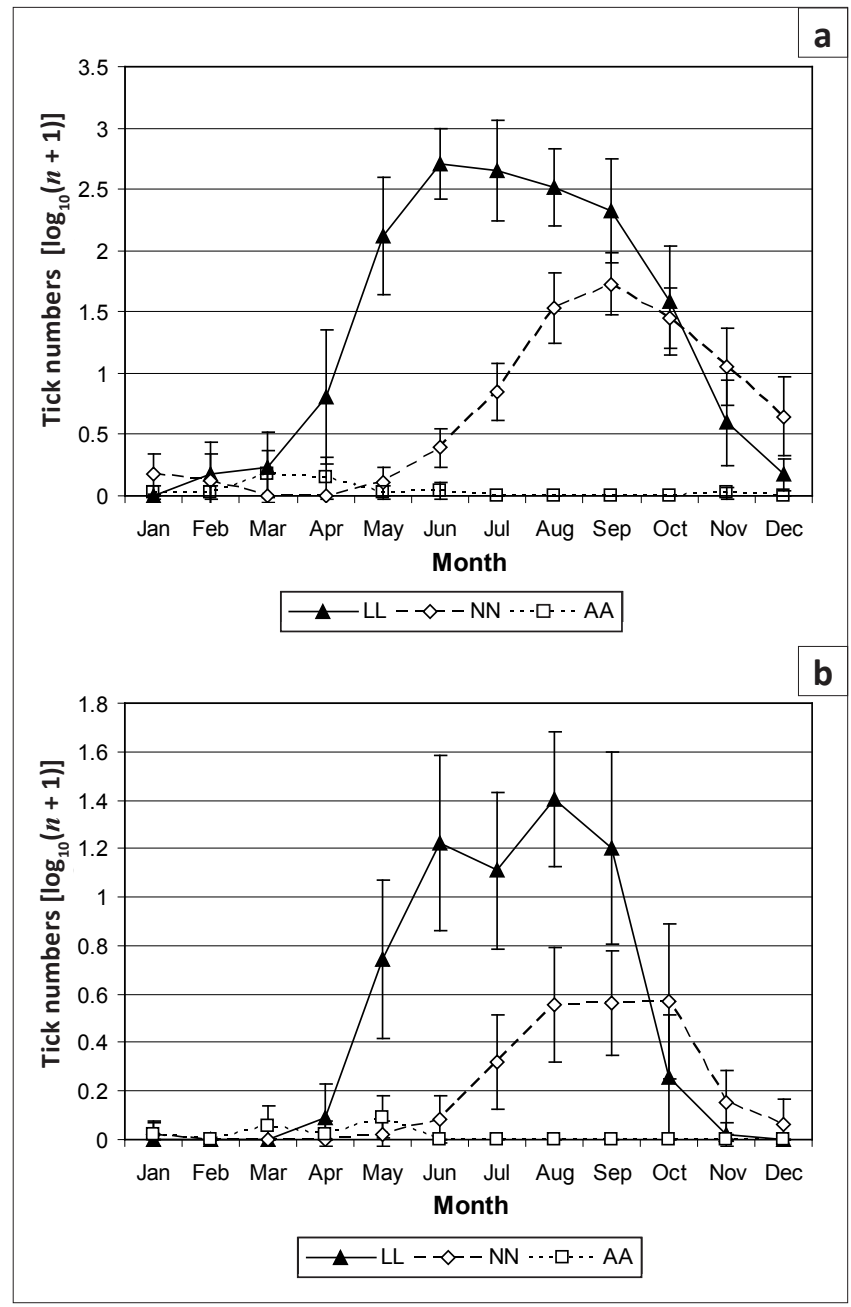

AA, adults; LL, larvae; NN, nymphs.

FIGURE 6: Mean ( $\pm 95 \%$ confidence interval) collections of all stages of Rhipicephalus zambeziensis per month at a) Skukuza and b) Nhlowa Road. pattern was most apparent prior to the 1991/1992 drought, when numbers were increasing, and after the turn of the century. While the distribution among habitats did not differ significantly between months, numbers of nymphs were much higher in the grassland than in the gullies from August to November, the period of peak activity. The habitat distribution of nymphs probably reflects habitat use of major hosts during the period of larval activity. Buffaloes expand their range in winter, with increased use of the uplands (Funston, Skinner \& Dott 1994), and impalas increase the percentage of time spent grazing, particularly after the spring rains (Wronski 2002). The shift in habitat use by these two species would have increased the number of larvae detaching in the grassland during the winter and spring. At Skukuza the majority of $R$. appendiculatus nymphs were collected in the woodland and gullies, reflecting the preferred habitats of the predominant hosts at this site.

Adult $R$. appendiculatus were collected most frequently in the gullies at both sites. This distribution may reflect the use of shaded areas by hosts in the summer and the impact of climatic stress. Short et al. (1989b) reported shorter duration of survival of adult $R$. appendiculatus in short grass habitats than in long grass habitats and Minshull and Norval (1982)
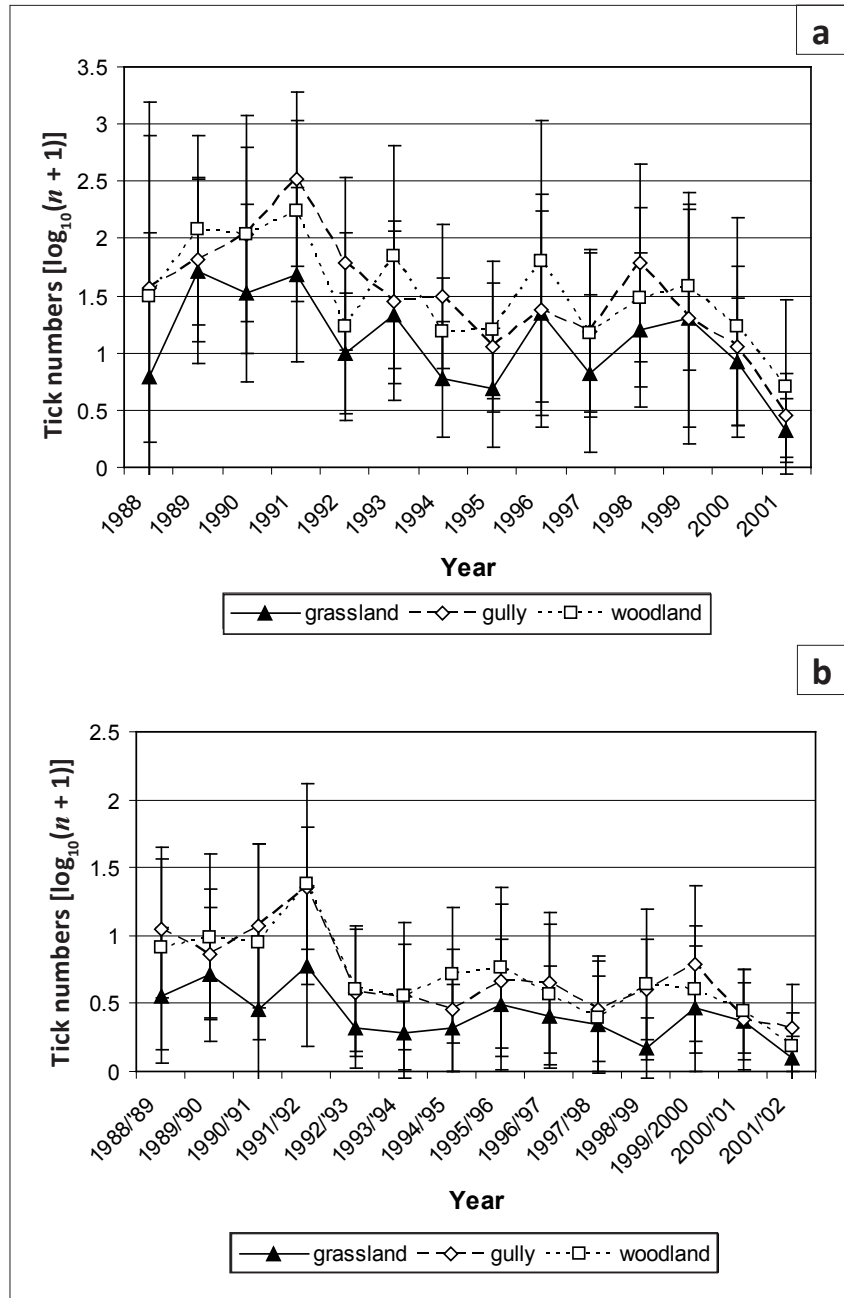

FIGURE 7: Mean ( $\pm 95 \%$ confidence interval) monthly collections of Rhipicephalus zambeziensis a) larvae and b) nymphs during the active periods per habitat per year at Skukuza. 
noted that the numbers and duration of activity of $R$. appendiculatus adults were substantially greater in the cooler, moister Julbernardia woodland than in the open grassland.

\section{Rhipicephalus zambeziensis}

Rhipicephalus zambeziensis is also a three-host tick. The preferred wild hosts are impalas and kudus (Horak et al. 1992, 2003; Walker et al. 2000). R. zambeziensis accounted for $38.3 \%$ of the ticks collected at Skukuza, but only $1.3 \%$ of the ticks collected at Nhlowa Road (Table 1). The predominance of $R$. zambeziensis in the riverine thickets is consistent with previous studies on free-living ticks and surveys of hosts in the two landscape zones (Horak et al. 1983b, 1993, 2003, 2006; Spickett et al. 1992). R. zambeziensis is present in the great river valleys and adjacent low-lying areas of southern African countries from Angola in the west to Tanzania in the east (Walker et al. 2000). The Nwaswitshaka River, along which the collections were made, flows into the Sabie River a few kilometres to the north of the Skukuza collection site. The Sabie River valley and its adjacent low-lying areas are considered the south-eastern limit of this tick's distribution (Walker et al. 2000).

At Skukuza the numbers of $R$. zambeziensis peaked in $1991 / 1992$, then declined to a nadir in 1994/1995, increased slightly from $1996 / 1997$ to $1999 / 2000$, and then declined again. At Nhlowa Road, the numbers increased until 1992/1993, declined to a nadir in 1994/1995, increased from $1995 / 1996$ to $1998 / 1999$, and then declined again. The trends in the numbers of $R$. zambeziensis until the mid-1990s were similar to those of $R$. appendiculatus at Nhlowa Road, and changes in ungulate nutritional status and populations may have had a similar influence on both tick species. However, unlike $R$. appendiculatus, the numbers of $R$. zambeziensis increased after the nadir, similar to the populations of $A$. hebraeum and $R$. decoloratus (Horak et al. in press), but unlike the latter two species, the populations of $R$. zambeziensis declined after the turn of the century.

The seasonality of $R$. zambeziensis was similar to that of $R$. appendiculatus, but the duration of peak activity was typically 1-2 months longer. At Skukuza the peak abundance of $R$. zambeziensis was later and the seasonal occurrence was longer in years with large numbers, similar to the patterns for $R$. appendiculatus at Nhlowa Road. The seasonal occurrence of $R$. zambeziensis at Nhlowa Road was similar to that at Skukuza in years when low numbers were collected.

The seasonal occurrence of $R$. zambeziensis at Skukuza corresponded to that on impalas and scrub hares in this area (Horak et al. 1993, 2003), although the duration of activity of the questing stages was longer than the duration of activity on the hosts. The duration of activity on impalas appears to correspond more closely to the duration of activity of $R$. zambeziensis in the grassland than with the duration of activity in the woodland and gullies. This probably reflects the seasonal shift from browsing to grazing by impalas (Wronski 2002) and the more favourable climatic conditions of woodland and gullies for the survival of the free-living stages during the winter and spring.

\section{Conclusion}

Questing ixodid ticks were collected by dragging the vegetation monthly in three habitats, namely grassland, woodland and gully, at two sites (Nhlowa Road, Landscape Zone 17 and Skukuza, Landscape Zone 4) in the KNP from August 1988 to March 2002. The study began towards the end of a wet period in the KNP and continued through the dry period into the subsequent wet period (Horak et al. 2011), which also provided an opportunity to examine the effect of changes in rainfall on the population dynamics of these two species in the KNP.

The predominance of $R$. appendiculatus in the Marula-Knob thorn savanna and of $R$. zambeziensis in the riverine thickets is consistent with previous studies on free-living ticks and surveys of hosts in these landscape zones (Horak et al. 1983b, 1993, 2003, 2006; Spickett et al. 1992). The host populations differ between the two landscapes zones (Horak et al. 2011) and the apparent differences in host preferences of these two species probably reflect differences in landscape preferences of their hosts rather than host selectivity.

The differences in the relative numbers of $R$. appendiculatus and $R$. zambeziensis at the two sites and the responses of their populations over time suggest that climatic conditions may be important in determining the population dynamics of these ticks at the interface of their distributions. In Zimbabwe, $R$. zambeziensis occurs in areas with an annual rainfall of less than $700 \mathrm{~mm}$ and average relative humidity less than 55\% and 70\% in the dry and wet months, respectively. R. appendiculatus, however, occurs in areas with an annual rainfall of more than $500 \mathrm{~mm}$ rainfall and relative humidity of $50 \%-70 \%$ and $70 \%$ - $85 \%$ during the dry months and wet months, respectively (Norval et al. 1982). At the beginning of the present study, $R$. appendiculatus predominated at Nhlowa Road, while $R$. zambeziensis predominated at Skukuza. The populations of both species declined after the 1991/1992 drought. At Skukuza the populations of $R$. zambeziensis recovered in the late 1990s, but then declined. In contrast, except for 1993, the populations of $R$. appendiculatus were highest at Skukuza in 2000 and 2001. At Nhlowa Road the populations of $R$. appendiculatus increased until 1991, declined to a nadir in 1996 and 1997, and then increased again. The populations of R. zambeziensis peaked in 1992, declined, and then increased again before declining towards the turn of the century. From 1995 to 1997, the numbers of R. zambeziensis exceeded the numbers of $R$. appendiculatus. The predominance of $R$. zambeziensis at Nhlowa Road and virtual disappearance of $R$. appendiculatus at Skukuza occurred towards the end of the dry cycle. In contrast, the populations of $R$. zambeziensis declined markedly at both sites during the period of above-average rainfall at the turn of the century, while the populations of $R$. appendiculatus increased. This is consistent with the findings of Madder et al. (2005) who, in their survival studies of these two species in Zambia, found R. appendiculatus to be confined to cooler and wetter conditions, while $R$. zambeziensis is better adapted to hotter and drier conditions. 
The changes in rainfall appear to explain the overall trends in the populations of the two tick species, but they do not explain the differences between the two sites because the average rainfall was similar, or slightly lower, at Nhlowa Road (Horak et al. 2011). However, relative humidity was generally lower at Skukuza than at Nhlowa Road, except during the mid-1990s when rainfall was higher at Skukuza than at Nhlowa Road. The increase in the numbers of $R$. zambeziensis at Nhlowa Road prior to the 1991/1992 drought coincided with a general decrease in relative humidity. $R$. zambeziensis continued to be more common than $R$. appendiculatus at Nhlowa Road during the mid-1990s when relative humidity was lower. However, the numbers of $R$. appendiculatus increased and the numbers of $R$. zambeziensis declined as rainfall and relative humidity increased towards the turn of the century. At Skukuza, the numbers of $R$. zambeziensis declined following the heavy rainfall in 1999/2000 when relative humidity was higher than that observed in the first years of this study. Thus, while rainfall may be important for determining population trends, relative humidity may be the factor determining local distributions.

\section{Acknowledgements}

We are indebted to SANParks for placing their staff and facilities in the KNP at our disposal. We gratefully acknowledge the assistance of Dr Leo Braack and Mr André Potgieter with arranging the logistics for the collections. Ms Heloise Heyne and Ms Andrea van Niekerk assisted with many of the field collections, as did a number of nature conservation and veterinary students. Our special thanks, however, are reserved for the SANParks, Skukuza staff, who were our armed guards and assisted with the collection of the many thousands of ticks from the flannel strips. The research was funded by the Faculty of Veterinary Science (University of Pretoria), SANParks, Bayer Animal Health, the University of the Free State and the National Research Foundation.

\section{References}

Acocks, J.P.H., 1988, Veld types of South Africa with accompanying veld type map, 3rd edn., Department of Agriculture and Water Supply, Pretoria.

Funston, P.J., Skinner, J.D. \& Dott, H.M., 1994, 'Seasonal variation in movement patterns, home range and habitat selection of buffaloes in a semi-arid habitat', African Journal of Ecology 32, 100-114. doi:10.1111/j.1365-2028.1994.tb00562.x

Gallivan, G.J., Culverwell, J., Girdwood, R. \& Surgeoner, G.A., 1995, 'Ixodid ticks of impala (Aepyceros melampus) in Swaziland: effect of age class, sex, body condition and management', South African Journal of Zoology 30, 178-186.

Gertenbach, W.P.D., 1983, 'Landscapes of the Kruger National Park', Koedoe 26, 9-121.

Horak, I.G., Potgieter, F.T., Walker, J.B., De Vos, V. \& Boomker, J., 1983a, 'The ixodid tick burdens of various large ruminant species in South African nature reserves', Onderstepoort Journal of Veterinary Research 50, 221-228.

Horak, I.G., De Vos, V. \& Brown, M.R., 1983b, 'Parasites of domestic and wild animals in South Africa. XVI. Helminth and arthropod parasites of blue and black wildebeest (Connochaetes taurinus and Connochaetes gnou)', Onderstepoort Journal of Veterinary Research 50, 243-255.

Horak, I.G., Boomker, J., Spickett, A.M. \& De Vos, V., 1992, 'Parasites of domestic and wild animals in South Africa. XXX. Ectoparasites of kudus in the eastern Transvaal Lowveld and the eastern Cape Province', Onderstepoort Journal of Veterinary Research 59, 259-273.
Horak, I.G., Spickett, A.M., Braack, L.E.O. \& Penzhorn, B.L., 1993, 'Parasites of domestic and wild animals in South Africa. XXXII. Ixodid ticks on scrub hares in the Transvaal', Onderstepoort Journal of Veterinary Research 60, 163-174.

Horak, I.G., De Vos, V. \& Braack, L.E.O., 1995, 'Arthropod burdens of impalas in the Skukuza region during two droughts in the Kruger National Park', Koedoe 38, 65-71.

Horak, I.G., Spickett, A.M. \& Braack, L.E.O., 2000, 'Fluctuations in the abundance of Boophilus decoloratus and three Rhipicephalus species on vegetation during eleven consecutive years', in M. Kazimírová, M. Labuda \& P.A. Nuttal (eds.), Proceedings of the $3^{\text {rd }}$ International Conference on Ticks and Tick-borne Pathogens, into the $21^{\text {st }}$ Century, Bratislava, Slovakia, August 30-September 3, 1999, pp. 247-251.

Horak, I.G., Gallivan, G.J., Braack, L.E.O., Boomker, J. \& De Vos, V., 2003, 'Parasites of domestic and wild animals in South Africa. XLI. Arthropod parasites of impalas (Aepyceros melampus) in the Kruger National Park', Onderstepoort Journal of Veterinary Research 70, 131-163.

Horak, I.G., Gallivan, J., Spickett, A.M. \& Potgieter, A.L.F., 2006, 'Effect of burning on the numbers of questing ticks collected by dragging', Onderstepoort Journal of Veterinary Research 73, 163-174.

Horak, I.G., Golezardy, H. \& Uys, A.C., 2007, 'Ticks associated with the three largest wild ruminant species in southern Africa', Onderstepoort Journal of Veterinary Research 74, 231-242.

Horak, I.G., Gallivan, G.J. \& Spickett, A.M., 2011, 'The dynamics of questing ticks collected for 164 consecutive months off the vegetation of two landscape zones in the Kruger National Park (1988-2002). I. Total ticks, Amblyomma hebraeum and Rhipicephalus decoloratus', Onderstepoort Journal of Veterinary Research 78(1): Art. \#32, 10 pages. doi:10.4102/ojvr.v78i1.32

Madder, M., Speybroeck, N., Bilounga, A., Helleputte, D. \& Berkvens, D., 2005, 'Survival of unfed Rhipicephalus appendiculatus and Rhipicephalus zambeziensis adults', Medical Veterinary Entomology 3, 245-250. doi:10.1111/j.13652915.2005.00566.x, PMid:16134972

Minshull, J.I. \& Norval, R.A.I., 1982, 'Factors influencing the spatial distribution of Rhipicephalus appendiculatus in Kyle Recreational Park, Zimbabwe', South African Journal of Wildlife Research 12, 118-123.

Norval, R.A.I. \& Perry, B.D., 1990, 'Introduction, spread and subsequent disappearance of the brown ear tick, Rhipicephalus appendiculatus, from the southern lowveld of Zimbabwe', Experimental and Applied Acarology 9, 103-111. doi:10.1007/ BF01198988

Norval, R.A.I., Walker, J.B. \& Colborne, J., 1982, 'The ecology of Rhipicephalus zambeziensis and Rhipicephalus appendiculatus (Acarina, Ixodidiae) with particular reference to Zimbabwe', Onderstepoort Journal of Veterinary Research 49, 181-190.

Ogutu, J.O. \& Owen-Smith, N., 2005, 'Oscillations in large mammal populations: are they related to predation or rainfall?', African Journal of Ecology 43, 332-339. doi:10.1111/j.1365-2028.2005.00587.x

Olwoch, J.M., Van Jaarsveld, A.S., Scholtz, C.H. \& Horak, I.G., 2007, 'Climate change and the genus Rhipicephalus (Acari: Ixodidae) in Africa', Onderstepoort Journal of Veterinary Research 79, 45-72.

Perry, B.D., Lessard, P., Norval, R.A.I., Kundert, K. \& Kruska, R., 1990, 'Climate, vegetation and the distribution of Rhipicephalus appendiculatus in Africa', Parasitology Today 6, 100-104. doi:10.1016/0169-4758(90)90224-R

Rechav, Y., 1979, 'Migration and dispersal patterns of three African ticks (Acari, Ixodidae) under field conditions', Journal of Medical Entomology 16, 150-163.

Short, N.J., Floyd, R.B., Norval, R.A.I. \& Sutherst, R.W., 1989a, 'Development rates, fecundity and survival of the developmental stages of the ticks Rhipicephalus appendiculatus, Boophilus decoloratus and B. microplus under field conditions appendiculatus, Boophilus decoloratus and B. microplus under field conditions in Zimbabwe', Experimental and Applied

Short, N.J., Floyd, R.B., Norval, R.A.I. \& Sutherst, R.W., 1989b, 'Survival and behaviour of the unfed stages of the ticks Rhipicephalus appendiculatus, Boophilus decoloratus and B. microplus under field conditions in Zimbabwe', Experimental and Applied Acarology 6, 215-236. doi:10.1007/BF01193981, Experimental and Applied

Spickett, A.M., Horak, I.G., Braack, L.E.O. \& Van Ark, H., 1991, 'Drag-sampling of freeliving ixodid ticks in the Kruger National Park', Onderstepoort Journal of Veterinary Research 58, 27-32.

Spickett, A.M., Horak, I.G., Van Niekerk, A. \& Braack, L.E.O., 1992, 'The effect of veldburning on the seasonal abundance of free-living ixodid ticks as determined by drag-sampling', Onderstepoort Journal of Veterinary Research 59, 285-292.

Walker, J.B., Keirans, J.E. \& Horak, I.G., 2000, The genus Rhipicephalus (Acari, Ixodidae): a guide to the brown ticks of the world, Cambridge University Press, Cambridge.

Whyte, I.J. \& Joubert, S.C.J., 1988, 'Blue wildebeest population trends in the Kruger National Park and the effects of fencing', South African Journal of Wildlife Research 18, 78-87.

Wronski, T., 2002, 'Feeding ecology and foraging behaviour of impala Aepyceros melampus in Lake Mburo National Park, Uganda', African Journal of Ecology 40, 205-211. doi:10.1046/j.1365-2028.2002.00348.x 